\title{
Comparing Color Words Comprehension in 36-71 Months Normal Preschool Persian Speaking Children
}

\author{
Nafise Hassanpour ${ }^{1}$; Nahid Jalilevand ${ }^{1,3}$; Elham Masumi ${ }^{1}$; Ali Ghorbani ${ }^{1}$; Mohammad \\ Kamali $^{2}$ \\ ${ }^{1}$ Department of Speech Therapy, School of Rehabilitation Sciences, Iran University of Medical Sciences, Tehran, IR Iran \\ ${ }^{2}$ Department of Rehabilitation Management, School of Rehabilitation Sciences, Iran University of Medical Sciences, Tehran, IR Iran \\ ${ }^{*}$ Corresponding author: Nahid Jalilevand, Department of Speech Therapy, School of Rehabilitation Sciences, Iran University of Medical Sciences, Tehran, IR Iran. Tel: +98-212222556, \\ Fax:+98-2122220946, E-mail: jalilevand.n@iums.ac.ir
}

Received: February 23, 2015; Revised: May 18, 2015; Accepted: May 24, 2015

\begin{abstract}
Background: Word comprehension starts between 5 - 9 months after birth and before babies can produce any single word. Although in most domains of word learning, comprehension starts before production, for some categories such as color words, this order can be reversed. Children start producing color words without having any adult-like comprehension of these words.

Objectives: The aims of the present study were to investigate the ability of Persian-speaking children to comprehend Berlin and Kay's 11 basic color words plus 5 color terms that are frequent in Persian, to compare girls' to boys' scores, and to determine the easiest and most difficult color words to comprehend for children.

Patients and Methods: In this cross-sectional descriptive-analytic study, 36-71 month-old Persian-speaking children ( $\mathrm{N}=81,43$ girls and 38 boys), divided into 3 age groups with a one-year interval, were selected from 7 kindergartens by convenience sampling method. The colorword comprehension subtest of the picture receptive vocabulary test for Persian children was used. The data was statistically analyzed with a Kruskal-Wallis test, Mann-Whitney U-test, and Spearman rank-order correlation using SPSS software.

Results: There was a significant difference between age groups to comprehend primary colors $(\mathrm{P}=0.001)$, early-secondary colors $(\mathrm{P}=$ $0.002)$, and 5 common color words $(\mathrm{P}=0.002)$. Girls' scores were significantly higher than boys' scores $(\mathrm{P}=0.028)$. The correlation between age and color-word comprehension was positive $(r=0.423)$.

Conclusions: The findings of this study indicate that older children are more proficient in comprehension of color words compared to younger children, and girls are more proficient than boys. The two easiest and two most difficult color words for children to comprehend within the 3 age groups were "black" and "red" and "phosphoric-green" and "turquoise-blue," respectively. There was a positive relation between age and color-word comprehension.
\end{abstract}

Keywords: Comprehension; Children; Preschool; Persian-Speaking; Color Words

\section{Background}

Generally, word comprehension starts between 5 -9 months after birth (1-4). At this point of development, children cannot produce any single word but can understand many words and some short phrases $(1,4)$. Although in most domains of word learning, word comprehension occurs before word production, this order can be reversed in some categories, such as color, number, time, and emotion $(5,6)$.

Because of the different ways that people talk about colors, color-term learning follows a different pattern in comparison to other categories (5). Following this pattern, children start producing color words without having any adult-like comprehension of these words (7).

Color-word learning poses a challenging situation for children $(7,8)$. Colors belong to a class of adjectives called dimensional adjectives that refer to perceptual properties of individual objects (5). In order to learn these adjectives, children require a lot of effort and time; con- sequently, this class of adjective is acquired slowly and effortfully (5). It has been claimed that the most difficult dimensional adjectives to learn for children may be color terms that can only be learned with explicit instruction (6).

The process of learning color terms such as "green," "blue," and "red" consists of three different steps. First, when a child is asked, "What color is this?" he/she can answer with a color word. Although his/her answer is usually syntactically correct, it might be semantically wrong. Next, in response to the order, "Give me the red one!" the child is expected to pick out the correct object among similar objects, which only differ by their color. The last step is the most difficult and usually occurs later. At this stage, children are able to categorize different objects based on their color by ignoring other aspects such as shape and size (5).

Early studies reported that children's knowledge about

Copyright (C) 2015, Semnan University of Medical Sciences. This is an open-access article distributed under the terms of the Creative Commons Attribution-NonCommercial 4.0 International License (http://creativecommons.org/licenses/by-nc/4.0/) which permits copy and redistribute the material just in noncommercial usages, provided the original work is properly cited. 
the meaning of color terms is not complete before 8 years of age, but recent research claims that nowadays children learn colors sooner than that, approximately around 3 or 4 years of age $(7,9)$.

More recently, one of the most interesting research topics addressed the delay between children's first production of color words and the adult-like understanding of these words. Two main perspectives could explain this delay between color-word comprehension and production $(7,9)$. In the first view, researchers believe that the delay between color-word production and adult-like understanding of color words is due to difficulties in abstracting color as a domain of meaning. In other words, it is a problem for children to accept colors as a relevant dimension of linguistic meaning. The second explanation for this delay refers to the gradual inductive process of determining the boundaries of individual color words $(7,9)$.

Based on the widely known study about color terms by Berlin and Kay, it is believed that there is a set of 11 basic color words, which are highly salient psychologically, used frequently in all languages, and consist of the following: "black," “white," “red," "yellow," "green," "blue," "brown," “orange," "purple,” “pink,” and” grey.”

Berlin and Kay divided these colors into two subcategories: "Primary" colors refer to the colors that are unique and cannot be generated by any other color combination. This group consists of "black," "white," "red," "yellow," "green," and "blue." Other colors can be obtained by some combination of primary colors and belong to "non-primary" colors, such as "brown," "orange," "purple," "pink," and "grey." For example, combining "red" and "yellow" generates "orange." Berlin and Kay's study also showed that the color learning process occurs in 7 hierarchic phases. Phases 1 to 5 are related to the primary subcategory and occur before phases 6 and 7 that are related to the secondary group (10-16). Although Berlin and Kay assumed that the order of learning color terms is similar among children from all over the world, some researchers reported that this assumption applies more to the production task ("What color is it?") than the comprehension task("Show me the red one!") $(13,14)$. There is also some evidence from several developmental studies that did not confirm this order $(13,14)$.

Bornstein and Corda investigated children's ability to discriminate between color boundaries. They found that discrimination within the intra-green boundary and intra-blue boundary is much more difficult than across the blue-green boundary $(13,14)$.

Pitchford and Mullen studied 2 -5 year-old Canadian children's abilities on production and comprehension of 11 primary and secondary basic color terms. Their results showed that 3-year-old children are more capable of naming primary colors than secondary colors, but this advantage was not seen at other ages and for the comprehension task (14).

LoBue and DeLoache investigated young children's col- or preferences in the first years of life. The results of their study revealed sex differences in young children's preference for the color pink, which manifested as both an increasing attraction to pink by young girls and a growing avoidance of pink by boys (17).

Wagner et al., using 3 different tasks, provided evidence of partial color-word understanding prior to production. The results of their study revealed that children often acquire partial comprehension for color words before beginning to produce them. This suggests that the delay between production and the acquisition of adult-like understanding cannot stem from problems with abstracting color but instead is best explained by a gradual inductive process of determining the boundaries of individual color words (9).

Al-Rasheed et al. studied the basic color terms in Arabic. Arabic children and adults were asked to write down all the color terms they could think of. The results of their study provided converging evidence that Arabic has 11 basic color terms that are consistent with Berlin and Kay's universal color categories (11).

Although numerous studies into the different dimensions of colors have been carried out in many countries, color words have not been the focus among Persian researchers. It has been claimed that "cultures drive language, and language drives the perception of color categories" (18). As linguistic and cultural factors are remarkable factors in color words learning we cannot generalize their results for Persian populations $(18,19)$.

\section{Objectives}

This study investigated the ability of 36-71 month-old Persian-speaking children to comprehend 11 basic color terms (introduced by Berlin and Kay) plus 5 common color terms in Persian. The main aims of this study were to compare the ability of color-word comprehension between 3 age groups, between boys and girls, and to determine the easiest and most difficult color words to comprehend for each age group.

\section{Patients and Methods}

\subsection{Participants}

In this cross-sectional descriptive-analytic study, a total of 81 Persian-speaking children ( 43 girls and 38 boys) between 36 and 71 months of age $(M=55.2, S D=10.5)$ participated. The children comprised 3 different age groups with the youngest group of 26 children between 36 and 47 months, the second group with 28 children between 48 and 59 months, and the oldest group with 27 children between 60 and 71 months. Participants were recruited over a four-month period from 7 kindergartens in Shahre-Ray. Because of the time limitation, the sampling was based on convenience; thus, kindergartens that were available and managers, teachers, and parents who agreed to participate in this study were selected. Based 
on several inclusion criteria, we selected the children who could participate in this study: Their first language had to be Persian, they had to be described as normal in general aspects of development by their parents, kindergarten teachers, and through informal assessments; they had to have no hearing or vision problems; they had to have no psychological problems, and their speech and language development and learning abilities had to be reported as normal by their parents, kindergarten teachers, and through informal assessments. The following exclusion criteria were applied: parent's unwillingness to let their child participate in this study, physical illness such as cold, headache, flu, otitis media, or mobility disorders; and children's unwillingness to take the test.

\subsection{Test Material}

In order to evaluate Persian-speaking children's ability to comprehend color words, the color-word comprehension subtest of the picture receptive vocabulary test for Persian children was used (content validity index or CVI $=1$, test-retest reliability $=81 \%$, and split-half reliability $=$ 91\%). This test measures the receptive (hearing) vocabulary of children, consists of 15 sub-tests for different categories, and evaluates comprehension of totally 240 words. Each category contains 16 color pictures (dimensions $9 \times 7 \mathrm{~cm})$. The test consists of a 60-page booklet with 4 full-color pictures arranged on each page. The children are required to select the picture that best illustrates the meaning of the stimulus word spoken by the examiner. If the chosen picture is correct, the child is given a score of 1 , otherwise a score of 0 is given.

\subsection{Procedure}

Initially, the purpose and process of the study were explained to kindergarten managers and teachers to consult with them. Therefore, they could select children who were suitable for our study. Next, we sent the parents a consent form, which explained the aims and procedure of our study, to obtain permission for participation of their children. In the consent form, parents were assured that their children's information would be regarded as strictly confidential and that taking the test would be totally free, safe, non-invasive, and optional for their children.

Two questionnaires also were attached to consent form. One questionnaire with 13 dichotomous questions was designed to check hearing problems and another contained 12 dichotomous questions about children's speech and language development, vision disorders, physical disorders, psychological problems and learning abilities. At the end of each questionnaire parents were asked to mention any special diseases or problems that their child had. In addition, children's medical records were considered. Each child who had inclusion criteria and his/her parents let us test him/her participated in our study. Prior to formal testing, time was spent to individually com- municate with each child to become acquainted with him/her and perform an informal language assessment. Then, if that child did not show any further problems, the testing process was described to him/her. Finally, once the child accepted to take the test, the testing procedure started. The child was asked to listen to the color word that the examiner articulated and to choose one of the four pictures that represented this color. If the child referred to the correct picture, he/she was given one point, otherwise no point was given. If a child did not respond to an item within approximately 10 seconds, the examiner prompted him/her by saying, "point to the picture you think might be correct." If the child still did not respond, the item was scored as an error and testing proceeded to the next item. All of the 4 color words for each page were queried but not at the same time. If a child pointed to one color with delay or doubt, that item was queried again at the end of the test to make sure that his/her answer was not correct by accident. Finally, each child's total score was calculated.

\subsection{Statistical Analysis}

Data were analyzed using SPSS 21 . Normality of the measurement data distribution was tested using the Kolmogorov-Smirnov one-sample test, which revealed that the distribution was not normal; thus, non-parametric tests were used. A Kruskal-Wallis test was applied to compare the different age groups' abilities to comprehend color words. A Mann-Whitney U-test was applied to perform pairwise comparisons between age groups and to examine if test scores were affected by gender. The relationship between age and test score was calculated using the Spearman rank-order correlation. For all statistical tests, the significance level was set at $\mathrm{P}<0.01$.

\section{Results}

In the current study, 81 children between the ages of 36 and 71 months, divided into 3 age groups (Table 1), participated. Berlin and Kay's 11 basic color words were divided into 3 groups similar to Pitchford and Mullen's study: primary colors (red, black, white, blue, green, and yellow), secondary-early colors (pink, purple, and orange), which appear at the same time as the primary colors, and secondary-late colors (brown and gray) that appear later than the others (14).

Table 1. Number of Children, Mean Age, and Standard Deviation in Each Age Group

\begin{tabular}{lcc}
\hline Age group, mo & Numbers & Values $^{\mathrm{a}}$ \\
\hline $\mathbf{3 6}-\mathbf{4 7}$ & 26 & $41.0 \pm 3.2$ \\
$\mathbf{4 8}-\mathbf{5 9}$ & 28 & $52.4 \pm 3.2$ \\
$\mathbf{6 0}-\mathbf{7 1}$ & 27 & $65.7 \pm 2.9$ \\
\hline
\end{tabular}

${ }^{\mathrm{a}}$ Data are presented as mean $\pm \mathrm{SD}$. 
We also added 5 common Persian color words, which are part of the color-word comprehension subtest of the picture receptive vocabulary test for children in Iran, to our test (maroon, phosphoric-green, navy-blue, jaspergreen, and turquoise-blue). The means and standard deviations of correct answers (raw scores) for each of the four color-word groups in the 3 age groups are shown in Table 2, and the percentages of correct answers for each color word is shown in Table 3.

To compare the different age group's abilities to comprehend the 4 color-word groups, a Kruskal-Wallis test was applied separately for each color-word group. The results of these tests showed that the 3 age groups were significantly different from each other in comprehension of primary colors $\left(\chi^{2}=14.50\right.$, P-value $\left.=0.001\right)$, early-secondary colors $\left(\chi^{2}=12.39\right.$, P-value $\left.=0.002\right)$, and 5 common

Table 2. Means and Standard Deviations of Raw Comprehension Scores for the Different Color Word Groups ${ }^{a}$

\begin{tabular}{lccc}
\hline Color group & \multicolumn{3}{c}{ Age group, mo } \\
\cline { 2 - 4 } & $\mathbf{3 6 - 4 7}$ & $\mathbf{4 8 - 5 9}$ & $\mathbf{6 0 - 7 1}$ \\
\hline Primary colors & $4.85 \pm 1.69$ & $5.79 \pm 1.13$ & $5.81 \pm 0.62$ \\
Secondary-early colors & $2.35 \pm 0.97$ & $2.93 \pm 0.26$ & $2.89 \pm 0.42$ \\
Secondary-late colors & $1.19 \pm 0.74$ & $1.36 \pm 0.67$ & $1.59 \pm 0.50$ \\
5 common colors in & $1.27 \pm 1.25$ & $1.36 \pm 0.91$ & $2.33 \pm 1.24$ \\
Persian & & & \\
\hline
\end{tabular}

a Data are presented as mean \pm SD.

Table 3. Percentages of Correct Answers for Each Color Word in the Comprehension Task Across the 3 Age Groups ${ }^{\text {a }}$

\begin{tabular}{lccc}
\hline \multirow{2}{*}{ Colors } & \multicolumn{3}{c}{ Age Group, mo } \\
\cline { 2 - 4 } Black & $\mathbf{3 6}$ - 47 & $\mathbf{4 8 - 5 9}$ & $\mathbf{6 0}-\mathbf{7 1}$ \\
\hline Red & 92.30 & 96.42 & 100 \\
\hline Pink & 92.30 & 96.42 & 100 \\
\hline Green & 92.30 & 96.42 & 96.29 \\
\hline Orange & 84.61 & 96.42 & 100 \\
\hline White & 84.61 & 96.42 & 100 \\
\hline Blue & 80.76 & 96.42 & 92.59 \\
\hline Purple & 80.76 & 96.42 & 88.88 \\
\hline Brown & 76.92 & 96.42 & 96.29 \\
\hline Gray & 73.07 & 96.42 & 96.29 \\
\hline Maroon & 69.23 & 89.28 & 100 \\
\hline Navy-blue & 53.84 & 46.42 & 62.96 \\
\hline Phosphoric-green & 42.30 & 50.00 & 74.07 \\
\hline Jasper-green & 42.30 & 39.28 & 66.6 \\
\hline Turquoise-blue & 23.07 & 17.14 & 25.92 \\
\hline a & 23.07 & 32.14 & 70.37 \\
\hline
\end{tabular}

a Data are presented as \%. color words $\left(\chi^{2}=12.17\right.$, P-value $\left.=0.002\right)$, but there was no significant difference between the 3 age groups in comprehending late-secondary colors $\left(\chi^{2}=4.03\right.$, P-value $=$ $0.133)$. To examine how the individual age groups differed from each other, a Mann-Whitney U-test was performed to compare pairs of age groups. Results showed that for primary colors, age group 1 was significantly different from age group $2(\mathrm{P}=0.001)$ and $3(0.007)$, but there was no significant difference between age group 2 and 3 ( $\mathrm{p}=$ 0.31 ); for secondary-early colors, age groups 1 was different from age group $2(\mathrm{P}=0.005)$ and $3(\mathrm{P}=0.007)$, but there was no significant difference between age groups 2 and $3(\mathrm{P}=0.94)$; for secondary-late colors, there were no significant differences between age groups 1 and $2(\mathrm{P}=$ $0.42)$, between age groups 1 and $3(P=0.04)$, and between age groups 2 and $3(\mathrm{P}=0.21)$. For the common colors, age group 1 was significantly different from age group $3(\mathrm{P}=$ 0.003 ), and age group 2 was different from age group 3 ( $P$ $=0.002)$, but there was no significant difference between age groups 1 and $2(\mathrm{P}=0.52)$.

To determine the amount and direction of correlation between age and color-word comprehension ability, a Spearman rank-order correlation coefficient was calculated, which showed that there was a direct and a low correlation between age and the children's ability to comprehend color words $(\mathrm{r}=0.423, \mathrm{P}<0.001)$.

In order to achieve the second goal of the study the role of gender in color comprehension a Mann-Whitney Utest was performed. The result of this test indicated that the girls' scores were significantly higher than the boys' scores $(\mathrm{U}=588.500, \mathrm{P}=0.028)$.

\section{Discussion}

The present study investigated color-word comprehension of 36 - 71 month-old Persian-speaking children across 3 age groups. For this purpose, the subtest of color-word comprehension of the picture receptive vocabulary test for Persian-speaking children was used.

Our results showed that older children were more capable in color-word comprehension than younger ones, and girls were more proficient than boys at this task. Color-word comprehension of children in age group 1 was lower than of children in age groups 2 and 3 . Age groups 2 and 3 did not show any significant differences in primary and secondaryearly colors. These findings indicated that although there was a remarkable development in color-word comprehension for primary and secondary-early colors from 36 - 47 to 48 - 59 months, the children did not show a considerable progress between 48 - 59 and 60 - 71 months.

The similarity of the mean scores for primary and secondary-early colors confirmed that comprehension of these colors appears at the same time and that they are learned at about 3 years of age.

There was no considerable enhancement in comprehension of common color words between ages 36 - 47 and 48 - 59 months, but there was a remarkable progress in this field after 5 years of age. 
In the 3 age groups, the lowest scores belonged to the secondary-late colors, in particular to "grey." This finding is consistent with the result of Pitchford and Mullen's study that showed that children prefer the secondary-late colors "brown" and "gray" significantly less than basic colors (14). Our results showed that except for the 4 colors "orange," "gray," "phosphoric-green," and "white," the percentage of correct answers in the comprehension task increased with age. Some probable reasons that can explain irregularities seen in these colors scores could be related to different personal experiences, specifically the age of the children, when they started going to kindergarten to have explicit instruction, the amount of color-word instructions and emphasis on teaching color material in kindergarten, the prevalence and usage of these colors in the child's daily life, or even the amount of personal interest in these colors.

The easiest color words for children to comprehend in the 3 age groups were "black" and "red." Almost all of the children pointed out the correct picture when they heard "black" and "red," which means that these two colors were very familiar to them. This finding is consistent with the result of Berlin and Kay's study. They reported that "black" and "red" are more common in many languages, so children learn them sooner than other colors. The main reasons that can explain these similarities between Berlin and Kay's study and ours refers to the universal nature of the neurophysiology of the human visual system, the fundamental nature of perception of primary colors, and the greater exposure to these colors $(10,14)$.

The most problematic colors to comprehend for Persianspeaking children were "phosphoric green" and "turquoise blue" and confirm the result of Franklin and Davies' study $(10,13)$ who argued, "Color perception is categorical. Although the color spectrum is continuous, it appears to be segmented into qualitatively different perceptual categories. Moreover discrimination of pairs of colors from adjacent categories is easier than discrimination of equivalently spaced colors in the same category" (10).

We can explain children's difficulties with comprehension of "phosphoric-green" and "turquoise-blue" based on Franklin and Davies' statement. Since "phosphoricgreen" is a combination of "green" and "yellow" and very similar to "light-green," most children assumed that it is just "green" and not "phosphoric." The same applies to "turquoise-blue," which is a combination of "blue" and "green" and very similar to "blue." We can accept the same reason for the children's low scores on "jaspergreen" between ages 3 and 5 years and "navy-blue" across all 3 age groups $(10,15)$. It should be mentioned that in Persian, "green" or "blue" is not used as a suffix to name different spectrums of these colors; thus, children cannot guess "yashmi” or its English equivalent "jasper-green," or "sormei" or its English equivalent "navy-blue" to refer to these colors except when they are instructed about their real meaning. Another reason that can explain the children's low comprehension ability is the limited information they might have about these colors.
Although there was a positive correlation between age and color-word comprehension, the coefficient was relatively low and some irregularities were observed in this pattern. For instance, the two younger age groups in this study showed slightly higher scores of comprehension for "white" than the oldest age group. This finding and the result of Pitchford and Mullen's study do not match Berlin and Kay's study, who claimed that the order of color-word learning is hierarchical and systematic; however, the result of our study did not confirm this order. In their hierarchy, color learning follows the order: "white," "black," "red," "green/yellow" or "yellow/green," and "blue" belonging to the primary group; and "brown," "orange," "pink," "purple," and "grey” belonging to the nonprimary group (10-16)

In our study, children were better at comprehending "green," "pink," and "yellow" than "white" while in Berlin and Kay's study "pink" was at the end of the hierarchy. Indeed, as Berlin and Kay claimed, "white" is a member of the primary group so children should learn it sooner than "pink" and know "white" better than "pink," which is a member of the non-primary group (14). However, the result of the current study, which is consistent with Pitchford and Mullen's study, revealed a different order of color acquisition in which children acquire an accurate knowledge of some primary and non-primary colors(14). Based on this finding, it can be concluded that colorword learning is essentially an age-related ability but critically depends on explicit instructions and the range of color-word usage in the linguistic input. Children are more proficient at comprehending colors that they have encountered before. Thus, a child can be labeled as normal regarding speech, language, and learning abilities by his/her parents and teacher and as a result of informal assessment, but can still show some difficulties in colorword learning.

The result of the current study will be useful for parents, speech and language pathologists, and kindergarten teachers to evaluate comprehension of color terms in children and to teach the colors that are suitable for their age.

\section{Acknowledgements}

This research was a part of a M.Sc. dissertation and was supported by grants provided by the Department of Speech Therapy affiliated to the Iran university of medical sciences. The authors would also like to thank the participants of the study.

\section{Funding/Support}

Iran University of Medical Sciences supported the study financially.

\section{References}

1. Thomley H. An investigation into the knowledge of receptive vocabulary in a first and second language A case study on Di- 
zygotictwins. Innervate Lead Undergraduate Work English Stud. 2011;3(1):453-79.

2. Hoff E. Language development. 5th ed. California: Wadsworth/Cengage Learning; 2013.

3. Hudry K, Leadbitter K, Temple K, Slonims V, McConachie H, Aldred C, et al. Preschoolers with autism show greater impairment in receptive compared with expressive language abilities. Int J Lang Commun Disord. 2010;45(6):681-90.

4. Gershkoff-Stowe L, Hahn ER. Word comprehension and production asymmetries in children and adults. J Exp Child Psychol. 2013;114(4):489-509.

5. Sandhofer CM, Smith LB. Learning color words involves learning a system of mappings. Dev Psychol. 1999;35(3):668-79.

6. Sandhofer CM, Smith LB. Why children learn color and size words so differently: evidence from adults' learning of artificial terms. J Exp Psychol Gen. 2001;130(4):600-20.

7. O'Hanlon CG, Roberson D. Learning in context: linguistic and attentional constraints on children's color term learning. J Exp Child Psychol. 2006;94(4):275-300.

8. Sandhofer CM, Thom EE. Taking the task seriously: reflections on measures of color acquisition.J Exp Child Psychol.2006;94(4):344-8.

9. Wagner K, Dobkins K, Barner D. Slow mapping: color word learning as a gradual inductive process. Cognition. 2013;127(3):307-17.

10. Franklin A, Davies IRL. New evidence for infant colour categories. Bri J Dev Psychol. 2004;22(3):349-77.
11. Al-rasheed A, Al-mohimeed N, Davies IRL. Berlin and Kay's Theory of Color Universals and Linguistic Relativity: The Case of Arabic.J Mod Educ Rev. 2013;3(5):366-86.

12. McManus IC. Note: half-a-million basic colour words: Berlin and Kay and the usage of colour words in literature and science. Perception. 1997;26(3):367-70.

13. Davies I, Corbett G, McGurk H, Jerrett D. A developmental study of the acquisition of colour terms in Setswana. J Child Lang. 1994;21(3):693-712.

14. Pitchford NJ, Mullen KT. The role of perception, language, and preference in the developmental acquisition of basic color terms. J Exp Child Psychol. 2005;90(4):275-302.

15. Davies IR, Corbett GG, McGurk H, MacDermid C. A developmental study of the acquisition of Russian colour terms. J Child Lang. 1998;25(2):395-417.

16. Ozgen E, Davies IR. Turkish color terms: Tests of Berlin and Kay's theory of color universals and linguistic relativity. J Linguist. 1998;36(5):919-56.

17. Lobue V, Deloache JS. Pretty in pink: The early development of gender-stereotyped colour preferences. Br J Dev Psychol. 2011;29(Pt 3):656-67.

18. Schirillo JA. Tutorial on the importance of color in language and culture. Color Res Appl. 2001;26(3):179-92.

19. Jameson KA. Introductory remarks on cognition, culture, and color experience. Cross Cult Res. 2005;39(1):5-9. 